\title{
EL DECLIVE DE LA IZQUIERDA Y LAS TRIBULACIONES DEL PARTIDO DEMOCRÁTICO ITALIANO1
}

\author{
The Decline of the Left and the Tribulations of the Italian Democratic Party
}

\author{
Mario Barcellona \\ Universidad de Catania \\ mbarcellona@lex.unict.it
}

Una reflexión sobre el declive de la izquierda no se puede poner en marcha sin tocar las otras dos cuestiones cruciales de este tiempo de la política, la de la crisis de la democracia y la de la explosión de los populismos.

\section{LO QUE UNIFICA ESTAS TRES CUESTIONES ES LA SINGULARIZACIÓN DE LAS SOCIEDADES}

La democracia está en crisis por la singularización, el imaginario que subyace al agotamiento de la política y la agonía de la representación.

La izquierda está en crisis porque la singularización ha quebrantado las originarias bases sociológicas y espirituales.

Los populismos -mejor-, estos populismos, son la forma en que se manifiestan el malestar y la protesta en los tiempos de la singularización.

Sin considerarlo en este contexto, el declive de la izquierda no se entiende ni es posible cuestionarse seriamente sobre lo que se debe hacer para ponerle remedio. Siempre que poner un remedio sea posible.

ESTA CONCATENACIÓN SE PUEDE EXPLICAR, UN TANTO SUMARIAMENTE, DE LA SIGUIENTE MANERA

La política supone la disponibilidad del orden y produce la representación como solidificación de las sociedades alrededor del modo de entenderlo; juntas generan archipiélagos, agregados en torno a condiciones materiales de existencia e instancias espirituales que se condensan en proyectos de orden y se proponen a la discusión pública.

La indisponibilidad del orden extingue la política y agota la representación; esta produce, por consiguiente, un pueblo reducido nuevamente a la dispersa multitud hobbesiana y, por lo tanto, impolítico e irrepresentable.

\footnotetext{
1 Título original: Il declino della sinistra e le tribolazioni del PD. Texto presentado por el Profesor Barcellona en el coloquio sobre su obra Dove va la democrazia? Scenari dalla crisi (Castelvecchi Editore, Roma 2018) organizado por el Comité Editorial de la revista Oxímora y el Grupo Isocratia de la Universidad de Barcelona. Traducción: Miguel Mandujano Estrada.
} 
Sin embargo, el agotamiento de la política y la representación no extingue el conflicto, sino que lo deja latente. Y precisamente por esto no suspende los procesos, materiales y espirituales, que atraviesan las sociedades, las desarticulan y producen el malestar y la protesta.

La latencia del conflicto dispersa las adhesiones de antes y renombra la protesta y el enfrentamiento, entregándolos a lo indistinto: lo indistinto de quien está fuera y se siente excluido y lo indistinto de quien está dentro y, sintiéndose amenazado, quiere proteger las condiciones de su propia identidad del modo en que, hasta ahora, ha estado en el mundo.

El populismo de hoy interpreta y da forma a esta indistinción a través del dispositivo de la externalización, que exculpa del fracaso y restringe el conflicto: el enemigo es el otro, el otro que está en el propio edificio y el otro que viene de fuera.

La izquierda ha permanecido, de alguna manera, ajena a este dispositivo, aunque también ha ocultado el conflicto a su mirada. De esta manera, se ha quedado ciega ante la protesta y sus razones. Extraña a la primera e indiferente a las segundas, se ha descubierto, más o menos conscientemente, de la parte de quien está dentro, protegida de aquel que es como es.

Esto ha producido que la protesta se vuelva contra ella, sobre todo contra ella, ya que se esperaba, por el contrario, que actuara para afrontar y contener la molestia social.

\section{LA SINGULARIZACIÓN QUE UNIFICA ESTE CAMBIO TIENE SU ORIGEN EN PROCESOS TANTO MATERIALES COMO ESPIRITUALES}

La indisponibilidad del orden tiene dos causas bien conocidas de las que, por consiguiente, es inútil hablar: la globalización y la deslocalización, por un lado, y la robotización y la informatización de la economía por el otro.

Tanto la una como la otra subvierten las relaciones industriales y modifican la estratificación social, cambiándola de su forma de pirámide a la de reloj de arena, con un bulbo arriba, donde están la élite, sus cortes y las legiones de minores a los que protege y un bulbo debajo, donde se acumula todo lo demás, mientras que para conectarlas solo hay un sutil canal que se estrecha poco a poco.

Sin embargo, nada podría haber ocurrido de la forma en que ha sucedido si a estos procesos materiales no los hubiera acompañado un cambio radical del imaginario individual y colectivo.

En esta modificación consiste, de hecho, la singularización: una forma de entenderse y entender las relaciones con los demás según la cual "cada uno por su cuenta", "cualquiera puede perseguir el éxito, siempre que sepa abrirse paso a codazos" y en todo caso, "cada uno se salva a sí mismo".

De aquí nace la contratación a la vida privada de las funciones públicas, la privatización de la esperanza y la universalización del proyecto que sustituye una sociedad mejor por la mejora de la propia situación personal. 
Este singular horizonte se inocula en el pueblo a través del consumo, la tecnología de las nuevas mercaderías y el aparato mass mediático. Sin embargo, está estructurado por el pensamiento único.

La crisis de la izquierda consiste precisamente en la incorporación incondicionada de tal pensamiento: el entusiasmo acrítico hacia la globalización y la "novedad informática", del cual normalmente se le acusa, tiene en esta incorporación su universal.

El manifiesto de esta incorporación se encuentra ya en la Tercera vía de A. Giddens y su conquista de la izquierda social democrática comienza con el triunfo del blairismo a finales del siglo pasado.

ESTA INCORPORACIÓN DEL PARADIGMA ORDOLIBERAL HA TRASTOCADO PENSAMIENTOS, PUNTOS DE REFERENCIA Y CÓDIGOS ANTROPOLÓGICOS DE LA IZQUIERDA DEL PASADO

Precisamente, esta se ha traducido:

- en el vuelco del mensaje tradicional: desde la predicación de la solidaridad hasta la mal disimulada aceptación del darwinismo social y la ostentosa admiración de sus muestras;

- en la búsqueda de otros interlocutores: desde el pueblo de antaño, de las fábricas, del campo y de las pequeñas empresas a los cenáculos de banqueros, editores y gerentes, a los salones de la gente de éxito y los intelectuales de moda;

- en la progresiva recolocación en la estratificación social: del trabajo y las clases medias productivas a la nueva burguesía de la intermediación que habita los centros urbanos y rurales;

- en la modificación antropológica de las clases dirigentes a todos los niveles de la organización sociopolítica de las sociedades: primero en la forma de progresivas re-comprensiones y re-representaciones de su viejo personal y luego directamente a través de la selección del nuevo;

- por último, en el abandono de la mirada del mundo y las categorías de lectura del cambio social: de la programación del desarrollo a una suerte de laisserfaire sostenido, cada vez más titubeantemente, en las políticas de la contingencia.

Y todo esto recurrentemente.

DURANTE ESTE TIEMPO, SIN EMBARGO, LOS PROCESOS ECONÓMICOS HAN CONTINUADO SACUDIENDO A LAS SOCIEDADES

Las sociedades se han fracturado y precarizado.

La riqueza se ha polarizado y la que se ha seguido redistribuyendo se ha ido canalizando progresivamente hacia protagonistas, actores secundarios y tropas de la economía de relación (la casta y sus numerosas familias). 
El trabajo se ha desvalorizado y sus directores colectivos, primero debilitados y luego burocratizados y ritualizados, se han disuelto poco a poco.

Se ha celebrado el divorcio del mundo del malestar y de la precariedad y, por lo tanto, de la demanda de justicia social de los partidos tradicionales de la izquierda.

Ha dado inicio la migración de gran parte de este electorado olvidado hacia el populismo y la abstención.

LOS PARTIDOS, QUE VENÍAN DE LA VIEJA IZQUIERDA SOCIAL DEMOCRÁTICA, HAN PENSADO EN ENCONTRAR OTRO ASENTAMIENTO SOCIAL, PERO SE HAN DIVIDIDO Y, FINALMENTE, DERRUMBADO

En su mayoría, la izquierda del pasado se ha convencido, o ha sido convencida, de que "se vence en el centro". De esta manera, se ha contentado con una espiral centrífuga, se ha vuelto hacia el otro lado y se ha dedicado a la ferviente y diligente búsqueda de otro electorado, uno más acomodado, biempensante y fascinado, sobre todo por los derechos civiles, que lo compensen del abandono de sus antiguas clases de referencia: fuera el lastre que detiene y adelante con los vientos que tiran.

Algunas veces, alguna fracción de esta izquierda ha reaccionado cediendo al ímpetu secesionista, principalmente orientado hacia atrás, que ha dado lugar al surgimiento de nuevos "arbustos": al pasado reciente del último compromiso de mínimos o al pasado remoto de las clases y la fábrica y la simplificación de sus correspondientes viejos lenguajes.

Sin embargo, ni la una ni la otra estrategia han captado el nuevo malestar: la primera, porque se aleja del supuesto de tener que ignorarlo; la segunda, porque la nueva molestia se da en las nuevas soledades del trabajo y de la vida; ya no habita en los lugares donde ella quisiera buscarla o -mejor todavía- ya no habita esos lugares con la antigua forma de pensar y, por tanto, no encuentra oídos que la escuchen y menos aún palabras que los abran.

En su mayoría, se ha limitado a mirar, con escepticismo y presunción, el surgimiento de formaciones de protesta que, a veces de modo consciente y decidido y otras en modo confuso e impreciso, se apropiaban de los símbolos y las insignias.

Finalmente ha llegado el colapso: primero Holanda, después Francia, más tarde Alemania, luego los Estados Unidos, al final Italia.

\section{A ESTE COLAPSO SOLO HAN SEGUIDO PALABRAS SIN MUCHO SENTIDO}

"No nos hemos sabido explicar". ¿Sobre qué? ¿Quizás, sobre que primero vienen las cuentas y el crecimiento y después (¿cuándo?) la supervivencia, un techo decente, las facturas y las hipotecas por pagar, el trabajo, las dificultades de la vida?

"Tenemos que volver a las periferias". Cómo decir que no, pero ipara hacer y decir qué? ¿Quizás, que por ahora no se puede hacer mucho por ellas y que deben esperar pacientes $y$, mientras tanto, arreglárselas?

"Debemos luchar contra las desigualdades y los privilegios". Ciertamente, pero ¿cuáles? Y sobre todo, ¿cómo? 
"Unámonos en un "Frente republicano" (miope) o en un "Frente progresista" (veleidoso). ¿Para hacer qué? ¿Quizás, para combatir a la plebe que se ha reunido bajo los populismos, para desenmascararlos mostrando que solo venden ilusiones y que no pueden cambiar nada en realidad? No obstante, dejando así a esta plebe donde está.

Hasta "salvemos Europa". ¿Pero qué Europa? ¿Aquella -para entendernos- del Manifiesto de Ventotene $y$, de una manera u otra, de la paz, la colaboración entre los pueblos, el desarrollo disponible para todos, la solidaridad, o la que inexorablemente ha empujado a Grecia al precipicio, aquella avara y condescendiente de las burocracias, que se deja escapar algún euro para quien le presta devoción o mucho más para quien está en su sala de control y, en cambio, permanece sorda a los programas de ampliación del trabajo y de garantía de la dignidad de sus ciudadanos más débiles?

Hay, ciertamente, un poco de retórica en estos interrogantes, y quizás pueda haber también una buena parte de falta de generosidad. Pero, al final, representan, bastante eficazmente, lo que las izquierdas derrotadas han sabido decir sobre los escenarios de Europa.

\section{EL BALANCE DE ESTA DISTORSIÓN Y LA DESORIENTACIÓN QUE LE HA SEGUIDO PARECE SINIESTRO}

La izquierda ya no reside en los partidos tradicionales de la izquierda y la que les ha sobrevivido está encerrada en alguna pequeña habitación desde donde únicamente profiere buenas palabras pero calla sobre las cosas que debería hacer para hacerlas realidad, y no por casualidad, porque las palabras permanecen inocuas y no llaman a las puertas de las cajas del Estado y/o de los ciudadanos, mientras que las cosas cuestan y, por tanto, dividen.

El pueblo de izquierdas ha terminado por no saber más cómo serlo y se ha quedado sin casa, se reagrupa desorientado ante los populismos y se aferra, confundido, a las palabras que, alternativamente evocan las dificultades inmediatas y expresan el resentimiento.

Un pueblo, pues, sin un sitio donde vivir y sin un alma, sin un horizonte al cual mirar y en el cual esperar.

Las cuestiones son, por lo tanto, dos: la casa y el alma. Pero esta última viene primero, porque sin alma no hay comunidad y la casa se reduce a un hotel por horas.

\section{¿QUÉ ALMA PARA LA IZQUIERDA?}

Sabemos -bien que mal- dónde comenzar a buscar esta alma: allá donde, en primer lugar, se manifiesta el malestar, un malestar que no es -como en el pasado- el que proviene de las condiciones materiales de la existencia, sino que va más allá y se extiende hasta el espíritu; así pues, pobreza, precariedad, deterioro urbano, pero también, y no en menor medida, pérdida de la esperanza, soledad, extravío del sentido de la vida. 
Y -bien que mal- sabemos también lo que puede simbolizar esta alma, incluso si de estos símbolos, al menos en parte, a menudo no en el mejor modo, se han apropiado otros.

Y son: supervivencia, empleo y, sobre todo, dignidad.

Hay que decirlo con claridad, sin timidez: no hay ningún nuevo inicio que no comience aquí, estudiando cómo se puede hacer y mejor de como los demás lo están replanteando, lo que las Ilamadas izquierdas de gobierno no han dicho o han dicho que no se puede hacer.

Tratar de enunciar alguna puede ayudar a entender.

Ante todo, hay que decir que, mientras se espera el crecimiento, los excluidos y los marginados no pueden ser abandonados a su suerte: una renta -como se la quiera llamar- sobre el umbral de la pobreza es -nos guste o no- el símbolo inmediato de una sociedad solidaria que la izquierda se ha dejado expropiar.

Cabe añadir también que una sociedad solidaria no es aquella que programa una reserva de desempleados y precarios subsidiados. Una sociedad solidaria tiene por ello su segundo y principal símbolo en el empleo, pleno, cualitativo, justamente retribuido y presidido por las garantías de la seguridad y la protección contra los abusos. Y puesto que el crecimiento podría no asegurar una mayor ocupación e, igualmente, no parece poder garantizar extensamente la calidad no precaria, debe tenerse en cuenta que el trabajo para todos podría requerir una amplia socialización, donde hay una base productiva desarrollada y firmes inversiones productivas específicas y cualificadas y donde esta base no existe y no hay un empleo que socializar.

Después del trabajo está el después-del-trabajo que, estando desarmado, debe estar todavía más custodiado por la dignidad -y este es el tercer símbolo-, la cual exige un tiempo razonable de tiempo de descanso y que la buena existencia de quien ya no trabaja sea un problema de la "ciudad" y no solo un problema de quien ha trabajado y de quien le ha dado trabajo. Y ya que otra antropología ha tomado el sitio de aquella, en otro tiempo exclusiva del homo faber, esta misma dignidad, que presidía el trabajo, requiere que, con igual intensidad, se consideren las proyecciones existenciales de socorro, lúdicas, cognitivas y creativas del ciudadano.

Finalmente, detrás de todo esto está la cuestión de Europa, respecto a la cual se deberían tener claras dos cuestiones: que las soberanías nacionales, en sí mismas, no están en grado de defenderse del poder excepcional de las potencias globales, por lo que una instancia supranacional es simplemente imprescindible, y que, sin embargo, el problema de las nuevas relaciones entre las soberanías nacionales y las instituciones de la Unión involucra a la misma democracia, con la consecuencia de que no puede ser dejado absolutamente en la mano de los soberanismos.

Ciertamente hay otras formas, de hecho -quizás- muchas otras. Pero estas constituyen la línea a lo largo de la que hoy transcurren los confines.

Son asuntos estos sobre los que pocos se atreverían a no estar de acuerdo hoy en día, aunque muchísimos les añaden la cláusula "después del crecimiento". Así que 
su prioridad o su secundariedad respecto al crecimiento es lo que, en un mundo donde las buenas intenciones se venden al mejor postor, hace la diferencia entre una izquierda que concuerde con su nombre y la derecha, como quiera que esta quiera llamarse.

\section{¿Pero cómo se puede desarrollar esta alma?}

La izquierda no ha sido nunca, ni puede convertirse ahora, en el partido de los mendigos.

Ingresos suficientes, empleo y dignidad son las banderas de los regimientos, no todavía la insignia que los unifica y no todavía el alma de la cual una nueva izquierda tiene vital necesidad.

Esta alma, para que se produzca, requiere trascendencia, tiene necesidad de que el singulus vuelva a trascender en una "parte" de la sociedad y que cada parte vuelva a trascender en un todo múltiple. O sea, tiene necesidad de que se vuelva a pensar la sociedad como un agregado de diversidad, como multiplicidad de condiciones diferentes de vida que solo juntas pueden salvarse y concebir la solidaridad como la única condición de esta salvación.

Esta trascendencia pasa, ante todo, por la superación del imaginario singular que hoy rige y unifica la dispersión del conjunto de los sistemas sociales. Requiere que el sitio del pueblo actual sea tomado por nuevas solidificaciones que se muevan desde las diferencias y produzcan agregaciones.

Sin embargo, diferencias y nuevas agregaciones solo pueden darse en nuevos lenguajes, nuevas praxis y nuevos lugares que, juntos, instauren un nuevo imaginario, individual y colectivo, que redetermine lo que cuenta y lo que no cuenta, lo que vale y lo que vale menos, es decir, que seleccione y jerarquice. Y que sobre estas bases se condense en un nuevo proyecto de orden, que debe ser nuevo no tanto por los ingredientes que utiliza, sino, esencialmente, por lo que los une, que dispone según prioridad y que, por lo tanto, le da el sabor.

\section{¿DÓNDE, FINALMENTE, PUEDE ESTA ALMA ENCONTRAR CASA?}

Las posibilidades -como es obvio- son solo dos: disponer de una casa que ya existe, reestructurándola, o construir una nueva.

Construir una nueva podría parecer la vía más directa, pero puede también parecer difícilmente realizable: se han hecho muchos intentos en la izquierda en esta dirección, incluso recientemente, y solo algunos parece que han tenido un cierto éxito, por lo demás, corriendo el riesgo de proximidad con los populismos (desde Podemos hasta France insoumise).

El hecho es que una nueva casa tiene necesidad de sedimentación, de recursos y de acreditación, y todas estas cosas, cuando no se heredan, solo se pueden procurar en virtud de movimientos que de alguna manera han echado raíces. Se repite a menudo que este es un tiempo de elevada movilidad electoral, pero se pasa por alto que los electores se mueven tendencialmente hacia donde ya se han producido solidificaciones, es decir, agregaciones y organizaciones que han desarrollado sím- 
bolos y movilizaciones coherentes. Tampoco en tiempos "volátiles" como estos pueden convencerlos, por lo tanto, las campañas de prensa, los llamamientos de intelectuales de prestigio o los comités de personal político ciertamente "de bien" pero todavía involucrado en experiencias anteriores, aún menos cuando el sentimiento que domina es -como lo es hoy- la decepción de la élite.

No puede entenderlo quien se obstina en no querer ver lo que se mueve en el fondo de los trastornos electorales día tras día; ¿cómo se puede pensar que una sociedad singularizada, sistemáticamente privada de cualquier referencia ideal y desgarrada por una fractura que indistintamente divide insider y outsider pueda reagruparse entorno a los manifiestos de los mass media, intelectuales y clase política que, con razón o sin ella, el "pueblo" atribuye indistintamente a la élite?

Casas de la izquierda ya construidas y todavía en buen estado, no parece que queden muchas a lo largo de Europa: en Francia y en Holanda están reducidas a escombros, en Alemania y en Suecia han visto restringida a sus respectivos mínimos históricos su viabilidad. Solo quedan en pie, aunque después de haber corrido graves peligros, en Gran Bretaña, en Portugal y, parcialmente, en España, o sea, justamente las que, hasta ayer, suscitaban incontables reservas en la familia del socialismo europeo.

En Italia, casas de la izquierda se diría que hay dos: un viejo edificio nobiliario, el del Partido Democrático (PD), ahora habitado por una burguesía pendenciera que ha olvidado el antiguo blasón, y un cobertizo, el de Libres e Iguales (LeU) junto al refugio de Poder al Pueblo (PalP), donde se albergan cadetes, recluidos en su mayoría en el culto de los orígenes, y exiliados de buena voluntad, aunque todavía vinculados a la madre patria y a sus tradiciones.

Desafortunadamente, las experiencias recientes muestran que el edificio de LeU no ofrece perspectivas alentadoras al Estado.

Lo habitan, junto a generosos militantes, antiguos narcisismos que difícilmente se harían a un lado, arraigadas ambigüedades que con mucho trabajo podrían ser realmente superadas y fundamentalismos insulsos que no parecería fácil extirpar.

Además, el reciente naufragio del propósito inicial de una gran coalición alternativa puede hacer pensar que el deudor insolvente no se hará fácilmente con un nuevo crédito.

Mientras del PalP se puede pensar que, con el mal ambiente que hay por las representaciones más revitalizadas de la izquierda no se puede negar que pueda crecer, no parece que pueda hacerlo en la medida necesaria para asumir esta tarea.

Podría parecer más realista, por lo tanto, preguntarse por la casa del PD. 
NOS GUSTE O NO, PARA LA IZQUIERDA SIGUE SIENDO DECISIVO ENTENDER QUÉ SERÁ, FINALMENTE, DEL PD

Para que esta alma reconquistada de la izquierda pueda pensar en encontrar refugio en la casa del PD, esta no debe ser demasiado estrecha y quienes la habitan, deben estar dispuestos a abrir la puerta.

El PD se ha alimentado de una ambigüedad constitutiva que, no obstante, desde hace un tiempo se ha agotado.

Nace al juntar dos ingredientes que virtualmente no combinarían mucho. Reivindica sus orígenes a partir de la unión de dos antiguas tradiciones solidarias, la socialista, proveniente del Partido Comunista Italiano (PCl) y la católica, que venía de la Democracia Cristiana (DC), las cuales buscaban la protección social y continuaban esperando una sociedad estructurada (organizaciones sindicales, ligas de campesinos, movimientos cooperativistas, sedes territoriales de los partidos, etc.). Sin embargo, ambas le encierran en el horizonte de un blairismo, más tarde revestido a la Clinton, que mira confiado a la nueva economía y una sociedad postideológica. De este modo, más abiertamente que antes, apuesta, por un lado, por la globalización y se vincula a los preceptos neoliberales, contando con el crecimiento abrumador que habrían debido desencadenar. Por el otro lado, hace suyo el modelo libertario y cosmopolita de la forma de pensar individual y de las relaciones sociales.

Durante sus primeros cinco años de vida, desde el inicio marcado por la inesperada crisis económica del 2008, se arrastra, por un lado, entre la convivencia forzada de una cansada memoria olivista ${ }^{2}$ y el impaciente novismo del personal político más reciente $y$, por el otro, la creciente hemorragia del electorado tradicional que ya no se siente representado.

Esta convivencia se rompe, finalmente, con el advenimiento de Renzi que, impugnando el desmantelamiento, levanta la bandera de una victoria sobre lo poco que quedaba de las viejas almas de la solidaridad. Estas, no obstante, habían ya perdido mucho de su color originario.

Sin embargo, mientras todo este proceso se cumple, la sociedad cambia: completa su singularización, se divide entre el nuevo reloj de arena social y la opinión pública y con esta el electorado comienza a dividirse entre la nihilista protesta de los populismos, a la que indistintamente se acogen cuantos se perciben caídos en el bulbo inferior del reloj de arena y la amenaza (a la disposición de los poderes, grandes o pequeños e incluso pequeñísimos, a los estilos de vida y a las posiciones de las que se jactan en el juicio social) que en estos populismos ven cuantos, con el rol de maiores o con el de minores y familias, se asignan al bulbo superior.

Como resultado de todo esto, la apariencia y el sentido con el cual se presenta ahora el PD son aquellos de una formación política de centro, cuyos grupos di-

${ }^{2}$ En referencia al Olivo (L'Ulivo), coalición de centro izquierda presidida por el ex primer ministro Romano Prodi entre 1996 y 2007. (N. del T.) 
rigentes, nacionales y periféricos, están en buena parte vinculados al bulbo superior del nuevo reloj de arena social, del cual, generalmente, se proponen como los mejores intérpretes.

El pensamiento que, en el fondo, lo posee es otro: el ordoliberal, que antepone a cualquier otro objetivo social el crecimiento e imagina curar los fracasos del mercado con más mercado y lo que le perpetúa, que tiene en la austeridad la única medicina de toda indisposición económica, tal vez con la advertencia de que, precisamente porque de una medicina se trata, es aconsejable reservarla a quien está enfermo, y por lo tanto, a quien está peor.

Su política confía visibilidad y consenso al homenaje a este nuevo mundo, al cual ofrece despojar al trabajo de sus viejos símbolos (Jobs $A c t^{3}$ ) y desvalorizar aún más las representaciones (rescisión de la concertación), hasta hacerlas caer en el escarnio de las expectativas sociales de los que quedan fuera (los jóvenes indolentes y puntillosos y aquellos perezosos, tumbados en el sofá en espera de la renta de ciudadanía). Aspectos, finalmente, bastante marginales, se podría decir, (que la protección del Estatuto garantizaba franjas limitadas de trabajo y empleo no se salva de seguro por ley, mientras los sindicatos tienen ya poco que ver con los de Lama y Carniti ${ }^{4}$. Es verdad. También los símbolos, "lugares" del imaginario, de los que está hecha la política, "gestos" que hablan en modo más elocuente que las palabras, anuncian que el "sol del futuro" y la "futura humanidad", juntos con el "biancofiore símbolo de amor" ${ }^{\prime \prime}$, le son ahora extraños; ya ni siquiera tienen sitio entre las viejas fotos de familia.

En gran parte, el estatuto antropológico de su personal político y de las clases que este personal involucra en su ascenso ha cambiado: el profesionalismo rampante en lugar de la vocación política (o social) y la cercanía a la élite en lugar del "pueblo disperso y olvidado".

Con esta apariencia y este sentido, el PD alcanza la derrota de primavera.

Esta derrota lo pone en la incómoda alternativa entre cambiar de piel y, sobre todo, de corazón y refugiarse en el horizonte de un centro declarado, "razonable", mercantil y europeo, cuyo rescate, no obstante, parece confiar únicamente a un apocalipsis de los mercados.

\footnotetext{
${ }^{3}$ Acrónimo de Jumpstart Our Business Startups Act, hace referencia a la reforma laboral promovida por el gobierno de Matteo Renzi (2014-2015) para flexibilizar el mercado y facilitar la contratación. (N. del T.)

${ }^{4}$ Luciano Lama (1921-1996) y Pierre Carniti (1936-2018), secretarios generales de la Confederación General Italiana del Trabajo (CGIL) entre 1970 y 1986 y de la Confederación Italiana de Sindicatos de Trabajadores (CISL) entre 1979-1985 respectivamente. (N. del T.)

5 "O bianco fiore, simbol d'amore" comienza la canción que se convirtió en el himno de la Democracia Cristiana. En las elecciones de 2001, la lista electoral presentada por el Centro Cristiano Democrático (CCD) y Cristianos Democráticos Unidos (CDU) se llamó también Biancofiore. (N. del T.)
} 


\section{LOS ESFUERZOS INFLUYENTES PARA UN PD A LA CABEZA DE UN CENTRO MÁS O MENOS EXPLÍCITO}

Esta es la vía que, sin muchas excepciones, señalan al PD las opiniones preponderantes.

Alguno querría darle un nuevo nombre (¿Frente republicano? ¿Frente de los progresistas?), algún otro lo vería abierto a un consistente restyling, quizá con algún toque de rosa. Pero, en el fondo, nada de esto es estrictamente necesario, porque esta identidad ya la posee el PD (en sí y en la percepción del electorado) y, sobre todo, porque ninguna de estas cambiaría en modo significativo su consistencia.

Alguno ha tratado de imaginar este escenario. $Y$ entonces ha pensado que "el centro, en la situación actual, es una especie de izquierda moderada", que esta "izquierda moderada" está constituida por el PD y que un PD, "relanzado y reconstruido" por un congreso, podría aspirar al 25\%. Pero, ya que incluso de esta manera este PD no tendría oportunidad de gobernar ni de constituirse en una oposición eficaz, se ha inventado un "Movimiento", el cual "debería reunir elementos del centro y de una izquierda que por alguna razón se ha alejado del partido" que se podría hacer con otro $25 \%$ que permitiría alcanzar la mayoría en un próximo nuevo parlamento.

Pero un "Movimiento" que reúne "centro e izquierda" es exactamente lo mismo que el de la "izquierda moderada" (que es un "centro") personificado por el PD (o sea, que pesca exactamente los mismos electores). De modo que este escenario evoca bastante la escena de una vieja película de Totò y Peppino en la que Totò, con ocurrencias geniales, confundía al pobre Peppino contando dos veces el mismo dinero.

Se podría decir que no solo el desierto crea espejismos, si no fuera porque el punto es otro y las opiniones acreditadas empujan, de manera compacta, en esta dirección. De hecho, razonamientos parecidos y los escenarios que surgen de ellos, son puestos en práctica como si el resultado electoral hubiera caído del cielo, como si no se originara en movimientos, conmociones, levantamientos profundos de la estructura social, de la forma en que los hombres han comenzado a entenderse y a entender las relaciones entre ellos y del "sentimiento" según el cual ahora perciben sus condiciones materiales y espirituales de existencia y toman una posición sobre el universo social en el que se inscriben.

Uno se pregunta, ¿cómo se llega a pensar que en unos cuantos meses más de un tercio del electorado italiano puede ser trasladado de una casilla a la otra, como si hubiera caído víctima de un momentáneo y limitado black-out cuando lo que ha sucedido en Italia no hace más que replicar lo que desde hace algunos años está sucediendo por todo Occidente?

En realidad, no hace falta mucha perspicacia política para entender que el establecimiento electoral de la política a la que se ha convertido y practicado el PD y de los personajes que de un modo u otro lo han puesto en escena, son, un punto más un punto menos (pero, quizás, más menos que más), el que las urnas de marzo 
han mostrado ${ }^{6}$ : esto -nos guste o no- es (contando quién entraría y quién saldría) su espacio en un universo social que ha cambiado como ha cambiado. Es del todo legítimo, por lo tanto, pensar en ocupar con estabilidad y orgullo este espacio, pero no parece muy serio presagiar dilataciones que lo conviertan en mayoría.

Solo un apocalipsis de los mercados podría cambiar las cosas. Aunque cuantos (más o menos abiertamente) lo auguran no tienen en cuenta que un apocalipsis como es inevitable- trastocaría todo y pondría en escena otros actores.

\section{UN PD REFUNDADO Y LA HEGEMONÍA SOBRE UN SECTOR PROGRESIVO AMPLIADO}

La alternativa a lo que se ha dicho antes solo puede ser una estrategia que despliega de una manera diferente al PD y le otorga la tarea de una hegemonía general sobre el sector del cambio.

Esta estrategia, no obstante, si quiere ser realista, no puede confiarse al enésimo "Constituyente" en tierra de nadie para una federación de izquierdas que deja a cada uno con su personal, al abrigo de su propio techo y dispuesto a hacerlo volver.

No puede tampoco agotarse en la invocación recurrente de una "apertura a la sociedad civil y a los movimientos", que produce, en mayor parte, cooptaciones oportunistas y subalternas de su personal y que a menudo ve al nuevo esterilizado y marginalizado en los nichos de las competencias especializadas, o diluidas en la abundancia de las representaciones parlamentarias.

Lo que debe ponerse en práctica es, más bien, una transformación del PD que le aporte la credibilidad que ha perdido en la izquierda y lo prepare para una lucha de hegemonía contra los partidos que, más o menos sinceramente y con diversa eficacia, se han apoderado del patrimonio que este había abandonado.

Una estrategia así puede tener un único objetivo, el de poseer el alma de la izquierda y darle finalmente una casa que esté a su altura. Pero supone, necesariamente, muchas condiciones: una estructura que abra los ojos y las orejas a lo que viene en la sociedad y que se reapropie de los instrumentos indispensables para interpretar el cambio; un horizonte que mueva desde esta alma y se articule en un orden; un proyecto razonable y realista que instituya prioridades ambiciosas y las persiga con convicción e intransigencia y, finalmente, otro lenguaje que aproveche lo nuevo de este tiempo y un personal político que hablándolo pueda ser creído.

Por lo tanto, se necesita la construcción de un pensamiento de la sociedad solidaria que se contraponga abiertamente al pensamiento único e intente reunir, pieza por pieza, los lineamientos de un orden más justo. Se necesita también la (re)construcción de una organización que se haga cargo de esta tarea y que promueva, testimonie y difunda este pensamiento.

Todo esto, evidentemente, no se hace de un día para otro.

\footnotetext{
${ }^{6}$ Elecciones generales del 4 de marzo de 2018, de las que emergió como principal fuerza política la coalición centroderechista Lega (Liga Norte). El Movimiento 5 Estrellas (M5S) fue segundo y tercero $-\mathrm{y}$ gran perdedor de la contienda- la coalición de centroizquierda encabezada por el Partido Demócratico (PD). (N. del T.)
} 
Hay, no obstante, dos pasos que son, ciertamente, muy difíciles de dar, y que sin embargo, constituyen el preludio necesario para esta estrategia, y por ello deben expresarse con claridad e implementarse de inmediato.

Quien se atribuye otra identidad, debe explicar cuál era su identidad anterior y en qué se distingue de la nueva.

El primer paso de quien reivindica una nueva identidad consiste, por lo tanto, en decir, abiertamente, lo que se ha hecho y que no se debería haber hecho, lo que no se ha hecho y que ahora se pretende hacer y lo que se pretende hacer de un modo eventualmente distinto de como otros han propuesto hacerlo.

Evidentemente, no se trata en absoluto de abjuraciones solemnes, sino de poner las condiciones necesarias para que se pueda creer que hay un nuevo buque que se mueve por una nueva ruta.

Por esta razón, no es suficiente proclamar, tal vez solemnemente, la indisolubilidad del rigor y la equidad, del crecimiento y de la igualdad o del mérito y la necesidad, ni tampoco largos manifiestos donde hay una palabra para todos y cada uno puede encontrar sin esfuerzo el sermón que querría escuchar. Se debe explicar hacia dónde se quiere ir realmente y cuáles son las estaciones del itinerario que se imagina: volver a estas cuestiones y responderlas abiertamente es el modo de hacerlo seriamente.

$\mathrm{Y}$ ya que no todo se puede hacer con todos, quien se ofrece a hacer algo tiene también el deber de decir con quién se propone hacerlo.

El segundo paso de tal estrategia consiste, por lo tanto, en declarar la disponibilidad a explorar las condiciones de alguna relación con el Movimiento 5 Estrellas (M5S).

Ninguno puede imaginar seriamente que el regreso de una izquierda pueda, de por sí, sanear el M5S y asignar a un PD, por más que se quiera refundado y renovado, porcentajes electorales que lo hagan autosuficiente. Por otro lado, los populismos han vendimiado en las filas de la izquierda, pero han cosechado también en otras partes. Han dado voz a otras sensibilidades, a modos de entender el mundo y las relaciones sociales que, para un perfil o para otro, no son simplistamente reducibles al "sentimiento" de la izquierda. Sería, por lo tanto, sociológica y políticamente ingenuo imaginar la nueva casa de la izquierda como el cuartel donde devolver "a quien ha desertado". Mientras es políticamente más apropiado, más que solamente realista, mirar a aquellos que no hayan estado arrasados por las derivas soberanistas y xenófobas como a un ámbito con el cual dialogar y hacia el cual volver a proponerse una influencia, que consiga orientar sin querer mandar (en lo que, quizás, parece que consiste, exactamente, la hegemonía pensada por Gramsci).

Sin embargo, la relación con el M5S significa algo más para el horizonte de la izquierda. Es la explicación de un proyecto de alianzas sociales (antes que políticas) sin la cual no hay una nueva izquierda posible, es la confirmación de que la izquierda vuelve a mirar al pueblo y no teme estar con él: porque el pueblo -nos guste o no- por una parte, quizás la más débil y disorientada, está todavía allí. 
Por ello, sin estos pasos el PD permanecerá sencillamente donde está, y la izquierda, siempre que "vuelva a mirar las estrellas", deberá buscar en otra parte su casa. 